\title{
The Myth of the High-Efficiency External-Combustion Stirling Engine
}

\author{
Paul H. Riley \\ Department of Electrical and Electronic Engineering, The University of Nottingham, Nottingham, UK \\ Email: paul.riley@nottingham.ac.uk
}

Received 6 November 2015; accepted 14 December 2015; published 17 December 2015

Copyright @ 2015 by author and Scientific Research Publishing Inc.

This work is licensed under the Creative Commons Attribution International License (CC BY). http://creativecommons.org/licenses/by/4.0/

c) (i) Open Access

\begin{abstract}
The reported discrepancy between theory and experiment for external combustion Stirling engines is explained by the addition of thermal resistance of the combustion gasses to the standard Carnot model. In these cases, the Stirling engine ideal efficiency is not as is normally reported equal to the Carnot cycle efficiency but is significantly lower. A new equation for ideal Stirling engine efficiency when the heat is obtained through external combustion without pre-heating the air, is presented and results for various fuels tabulated. The results show that petrol and diesel, internal combustion engines (Otto cycle) have a higher ideal efficiency than the Stirling engine. When comparing thermoacoustic engines heated by wood, efficiency should not be quoted as a percentage of the Carnot efficiency, but against a figure $48 \%$ lower than Carnot. The effect is not seen with electrically heated rigs, solar or nuclear fission heated engines.
\end{abstract}

\section{Keywords}

Carnot Cycle, Stirling Cycle, Rankine Cycle, Otto Cycle, Thermoacoustic, Heat-Engine, External Combustion, Internal Combustion, Combustion-Thermal-Resistance

\section{Introduction}

The maximum theoretical efficiency of the Stirling cycle is often quoted as the same as the Carnot efficiency [1]:

$$
\eta=\left(1-\frac{T_{c}}{T_{h}}\right) .
$$

The rationale behind writing this paper is to provide a new upper limit to the efficiency of external combustion Stirling engines and hence an explanation for the often reported low measured efficiency of Stirling engines 
in real-world external-combustion situations, compared with theoretical or rig results. Hopefully researchers and lecturers will include this paper's finding in their teaching of Stirling engines.

There are many references to a discrepancy between theoretical and experimental efficiency with the Stirling Cycle. Thermoacoustic rig test results using electrical heating on the hot heat exchanger have shown impressive thermal efficiencies of over 18\% [2] that are not reproduced using external combustion processes. This is because (1) is only true where the heat is supplied at a fixed temperature, such as in solar, through electrical heating, or a fission source. In such applications, the correlation of theory with experiments is within the expected experimental error. For example, use of plutonium as a heat source in a thermoacoustic engine [3] has an agreement of $15 \%$ between simulation and experiment with a stated thermodynamic efficiency of $18 \%$. In thermoacoustic tests with electrical heaters agreement between DeltaEC [4] simulation and experiment varies between about $40 \%$ [5] and $15 \%$ [6].

However, work on a swash plate V4X2 Stirling engine for automotive use [7] noted “... a power drop phenomenon [that] was [not] fully understood. The design manager had been misguided by too optimistic calculations by the Heat Transfer group: The cause was insufficient heat transfer capacity on the outside of the heater...”

Other automotive applications such as the Philips engine [8] have also shown an unexplained loss of efficiency.

More recently, modelling of an alpha Stirling engine for automotive [9] use implies that an external combustion Stirling engine is more efficient than a Diesel engine and that the only issue is the time for the engine to heat up and hence power available. However, the same report discusses a "50\% unknown efficiency degradation".

The apparent discrepancy between theory and experiment has also been attributed to pressure gradients in the thermoacoustic regenerator, and much work undertaken to mathematically model regenerator performance [10]. Lower than expected efficiencies have been reported in other works [11]-[16].

By modelling the entire system, including combustion, this paper presents a more accurate upper bound for external combustion Stirling engine cycle efficiency and better explains the discrepancies. When heating of the hot heat exchanger is by external combustion, efficiency is much less than the Carnot efficiency even in the idealised case.

\section{Methodology}

In this paper, we have augmented the maximum theoretical Carnot efficiency for specific fuel types using the model in Figure 1.

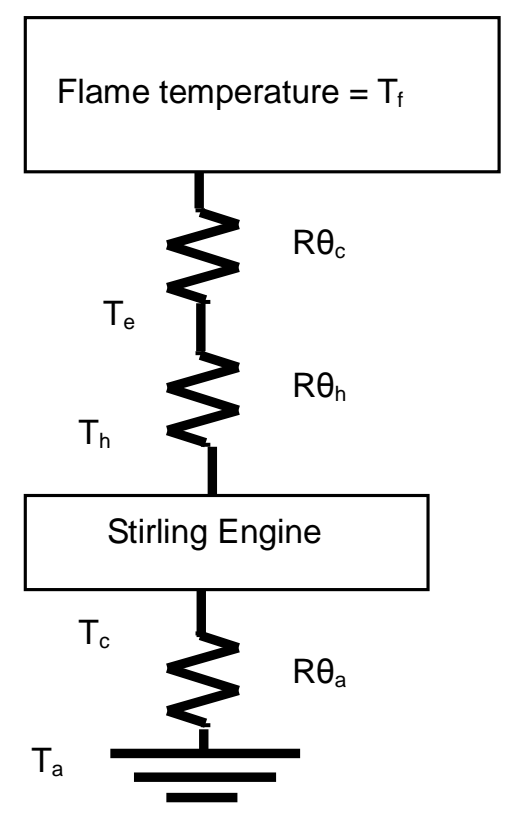

Figure 1. Model for fuel heated Stirling engines. 
In the ideal case, with perfect heat exchangers:

$$
R \theta_{h}=R \theta_{a}=0 \text {, and hence } T_{e}=T_{h} \text { and } T_{c}=T_{a} \text {. }
$$

It should be noted that $R \theta_{c}$ is a function of the combustion gas itself and is independent of the heat transfer mechanism, i.e. it applies equally to radiation, conduction or convection mechanisms and where:

$$
R \theta_{c}=\frac{1}{C_{p c} \dot{m}_{c}} .
$$

The flame at a temperature $T_{f}$ passes heat through the thermal resistances to the surrounding temperature $T_{a}$. So that heat available from combustion is

$$
Q_{c}=\frac{T_{f}-T_{a}}{R \theta_{c}} .
$$

And heat supplied to the Stirling Engine (SE) is:

$$
Q_{S E}=\frac{T_{f}-T_{h}}{R \theta_{c}} .
$$

The difference between $Q_{c}$ and $Q_{s e}$ being the heat lost in the exhaust gas.

Inspecting Equations (5) and (1) show that when $T_{h} \rightarrow T_{f}$ heat available to the $S E$ approaches zero and when $T_{h} \rightarrow T_{c}$ the Stirling efficiency drops. In both cases the overall engine efficiency $\eta_{S E} \rightarrow 0$.

For the general case where the fuel may contain water (for example wood), mass flow of the combustion products is the sum of its constituents:

$$
\dot{m}_{c}=\dot{m}_{f}+\dot{m}_{a}+\dot{m}_{w}
$$

and letting

$$
A_{f}=\frac{\dot{m}_{f}}{\dot{m}_{a}} \text { and } R_{w}=\frac{\dot{m}_{w}}{\dot{m}_{f}} .
$$

The specific heat of the combustion products is a function of fuel, air and fuel moisture content given by:

$$
C_{p c}=C_{p f}+C_{p a} X_{a} A_{f}+C_{p w} R_{w} .
$$

The heat available from combustion is reduced due to the evaporation of water content in the fuel, so:

$$
Q_{c}=\dot{m}_{f} C_{v f}-m_{w} L_{h} .
$$

Assuming no dissociation of component gasses, the idealised flame temperature is:

$$
T_{f}=\frac{\dot{m}_{f} C_{v f}-m_{w} L_{h}}{C_{p c} \dot{m}_{c}}+T_{c} .
$$

Making substitutions from (6) and dividing by fuel mass flow rate gives:

$$
T_{f}=\frac{C_{v f}-R_{w} L_{h}}{C_{p f}+X_{s} A_{f} C_{p a}+R_{w} C_{p w}}+T_{c} .
$$

Maximum work output from the Stirling engine is:

$$
W_{S E}=Q_{S E}\left(1-\frac{T_{c}}{T_{h}}\right) .
$$

Defining overall efficiency as

$$
\eta_{S E}=\frac{W_{S E}}{Q_{c}}
$$


And substituting from Equations (4), (5) with

$$
K=-\frac{C_{p f}+X_{s} A_{f} C_{p a}+R_{w} C_{p w}}{C_{v f}-R_{w} L_{h}}
$$

gives:

$$
\eta_{S E}=K\left(T_{h}+\frac{T_{c} T_{f}}{T_{h}}-T_{f}-T_{c}\right)
$$

Differentiating and setting:

$$
\frac{\partial \eta_{S E}}{\partial T_{h}}=0
$$

Gives the maximum efficiency condition when:

$$
T_{h}=\sqrt{T_{f} T_{c}} .
$$

\section{Results and Discussion}

The results for different fuels, using Equations (11), (15) and (17) are shown on Table 1. The Carnot efficiency is defined as [1]:

$$
\eta_{\text {carnot }}=\left(1-\frac{T_{a}}{T_{f}}\right) .
$$

The column $\eta_{S E}$, shows the idealised efficiency of an external combustion Stirling engine assuming perfect heat exchangers for the hot and ambient side.

$\eta_{S E}$ is the maximum theoretical efficiency of the fuels shown and can be seen that it varies between $39.3 \%$ for wood to $53.3 \%$ for hydrogen, which represents a reduction from the normally quoted maximum (Carnot) $S E$ efficiency (shown as "Ratio" on the table) of $48.2 \%$ and $58.8 \%$ respectively.

All the conditions are for use with air as the oxidising agent at standard pressure and without any pre-heating.

Wood combustion particularly when using cut branches is highly variable and heat produced depends on how dry the wood is and how well the fire is made. The values of 50\% excess air (Xs $=1.5$ ) and 15\% moisture content are considered the best achievable conditions.

The Diesel figures show a 50\% excess air value to compare with the Otto cycle discussed in the next section. Without the excess air, results are very similar to the Petrol figures.

Table 1. Comparison of engine efficiency for different fuels.

\begin{tabular}{ccccccccc}
\hline \multirow{2}{*}{ Fuel } & \multicolumn{7}{c}{ Efficiency result } \\
\cline { 2 - 9 } & $\eta_{S E}$ & Carnot & Ratio & $X_{s}$ & $A_{f}$ & $C_{v f}$ & $C_{p f}$ & $R_{w}$ \\
\hline Wood & $39.3 \%$ & $81.5 \%$ & $48.2 \%$ & 1.5 & 6 & 15,000 & 1.8 & $15.0 \%$ \\
Petrol & $51.7 \%$ & $89.8 \%$ & $57.6 \%$ & 1 & 14.7 & 45,000 & 2.22 & $0.0 \%$ \\
Diesel & $46.2 \%$ & $86.5 \%$ & $53.4 \%$ & 1.5 & 14.5 & 46,000 & 2.22 & $0.0 \%$ \\
Methane & $52.9 \%$ & $90.5 \%$ & $58.5 \%$ & 1 & 17.19 & 55,500 & 2.22 & $0.0 \%$ \\
Propane & $53.1 \%$ & $90.6 \%$ & $58.6 \%$ & 1 & 15.67 & 50,300 & 1.67 & $0.0 \%$ \\
Methanol & $52.2 \%$ & $90.1 \%$ & $57.9 \%$ & 1 & 6.47 & 23,000 & 1.93 & $0.0 \%$ \\
Ethanol & $52.3 \%$ & $90.2 \%$ & $58.0 \%$ & 1 & 9 & 30,000 & 1.88 & $0.0 \%$ \\
Hydrogen & $53.3 \%$ & $90.7 \%$ & 58.8 & 1 & 34 & 141,790 & 14.3 & $0.0 \%$ \\
\hline
\end{tabular}


Table 2. Comparison of external combustion Stirling with internal combustion engine.

\begin{tabular}{cccc}
\hline & & Efficiency for given compression ratio & \\
\cline { 2 - 4 } Fuel type & $\eta_{S E}$ & Otto cycle & $r$ \\
& $51.7 \%$ & $60.2 \%$ & 10 \\
Petrol & $46.2 \%$ & $69.8 \%$ & 20 \\
\hline
\end{tabular}

\section{Comparison with Other Cycles}

\subsection{Otto Cycle}

The maximum efficiency of an ideal Otto cycle engine, is given by [1]:

$$
\eta_{\text {ideal }}=\left(1-\frac{1}{r^{\gamma-1}}\right) \text {. }
$$

From Table 2 and using representative compression ratios of 10:1 for petrol and 20:1 for compression ignition (Diesel) engines, it can be seen that the ideal internal combustion engine efficiency is significantly higher than external combustion, thus exposing the Stirling engine myth.

\subsection{Rig Testing}

The results in the previous section go some way to explaining the discrepancy between the observed theoretical and experimental results for external combustion. However, there are cases where Equation (1) does hold. Many Stirling or thermoacoustic engine experiments use electrical heating to simulate the external combustion process. In such cases heat transfer from the electrical heater to the HHX is by a combination of radiation, convection and conduction, with the proportion of each depending on relative temperatures. The temperature of the heating coil will be higher than $T_{e}$ so as to transfer the heat. However, this temperature should not be confused with $T_{f}$, which is a fuel flame temperature or $R \theta_{c}$ which is thermal resistance based on combustion products. The difference in perspective arises from heat losses. With electrical heating, coil temperature increases do not increase losses, as the heat input is dependent on the product of coil voltage and current. There is still an $R \theta$ value but this is a method of determining coil temperature rise and does not directly affect losses. There may be other secondary and parasitic losses due to ineffective insulation, where increased coil temperature increases heat to the environment that bypasses the engine, but in the ideal case these losses are zero.

\subsection{Solar and Nuclear Power}

Equation (1) is still valid for any heat source that retains its temperature when the $S E$ absorbs heat. One typical example is solar radiation, where the temperature of the sun's surface does not change no matter how much power earth-based Stirling engines absorb. Another is in heating with nuclear fission, where the concept of $T_{f}$ is not valid.

\section{Conclusions}

The ideal Stirling cycle for external combustion engines that use non-pre-heated air as the oxidiser is always significantly lower than the equivalent Carnot cycle engine and for commonly used fuels is lower than the ideal Otto cycle efficiency.

The $\eta_{S E}$ measure gives a more accurate representation of the idealised efficiency of the external combustion Stirling engine cycle.

When modelling the efficiency of external combustion Stirling cycles, the effective thermal resistance of the combustion products should be included in the calculation.

The ideal Stirling engine gives lower efficiency for automotive applications than conventional Otto cycle engines.

\section{Acknowledgements}

This work was sponsored by EPSRC grant EP/J013986/1. 


\section{References}

[1] Eastop, T.D. and McConkey, A. (1993) Applied Thermodynamics for Engineering Technologists. Longman, Essex.

[2] Wu, Z.H., Zhang, L.M., Dai, W. and Luo, E. (2014) Investigation on a 1 kW Travelling-Wave Thermoacoustic Electrical Generator. Journal of Applied Energy, 124, 140-147. http://dx.doi.org/10.1016/j.apenergy.2014.02.063

[3] Backhaus, S., Tward, E. and Petach, M. (2004) Travelling-Wave Thermoacoustic Electric Generator. Applied Physics Letters, 85, 1085-1087. http://dx.doi.org/10.1063/1.1781739

[4] Swift, G.W. (2002) Thermoacoustics: A Unifying Perspective for Some Engines and Refrigerators. Acoustical Society of America, New York.

[5] Abdulrahman, S., Abduljalil, A., Yu, Z., Jaworski, A.J. and Shi, L. (2009) Construction and Performance Characterization of the Looped-Tube Travelling-Wave Thermoacoustic Engine with Ceramic Regenerator. Proceedings of World Academy of Science, Engineering and Technology, 37.

[6] Luo, E., Wu, Z.H., Dai, W., Li, S.F. and Zhou, Y. (2008) A 100 W-Class Travelling-Wave Thermoacoustic Electricity Generator. Chinese Science Bulletin, 53, 1453-1456. http://dx.doi.org/10.1007/s11434-008-0200-1

[7] Lundholm, G. (2002) The Experimental V4x Stirling Engine-A Pioneering Development. Ph.D. Thesis, Lund University, Sweden.

[8] Hargreaves, C.M. (1991) The Philips Stirling Engine. Elsevier Science Publishers, Amsterdam.

[9] Vinoth-Kumar, M. (2014) Modification of an Alpha Stirling Engine with an [sic] Venturi Based Working Fluid Control System to Promote Its Automotive Applications. International Journal of Mechanical Engineering and Robotics Research, 3, 101-113.

[10] de Boer, P.C.T. (2007) Basic Limitations on the Performance of Stirling Engines. Transactions of the ASME, 129, 104-113. http://dx.doi.org/10.1115/1.2204629

[11] Yu, Z., Jaworski, A.J. and Backhaus, S. (2010) A Low-Cost Electricity Generator for Rural Areas Using a Travelling Wave Looped-Tube Thermoacoustic Engine. Journal of Power and Energy: Proceedings of the IMechE-Part A, 224, 787-795. http://dx.doi.org/10.1243/09576509JPE864

[12] Chen, B., Abdalla-Abakr, Y., Riley, P.H. and Hann, D.B. (2012) Development of Thermoacoustic Engine Operating by Waste Heat from Cooking Stove. AIP Conference Proceedings, 1440, 532-540. http://dx.doi.org/10.1063/1.4704259

[13] Yu, Z., Jaworski, A.J. and Backhaus, S. (2012) Travelling-Wave Thermoacoustic Electricity Generator Using an UltraCompliant Alternator for Utilization of Low-Grade Thermal Energy. Applied Energy, 99, 135-145. http://dx.doi.org/10.1016/j.apenergy.2012.04.046

[14] Chen, B.M., Riley, P.H., Abdalla-Abakr, Y., Pullen, K., Hann, D.B. and Johnson, C.M. (2013) Design and Development of a Low-Cost, Electricity-Generating Cooking Score-Stove ${ }^{\mathrm{TM}}$. Proceedings of the Institution of Mechanical Engineers, Part A: Journal of Power and Energy.

[15] Chen, B.M., Riley, P.H., Abdalla-Abakr, Y. and Hann, D.B. (2012) Development and Assessment of Thermoacoustic Generators Operating by Waste Heat from Cooking Stove. Engineering, 4, 894-902. http://dx.doi.org/10.4236/eng.2012.412113

[16] Jaworski, A.J. and Mao, X. (2013) Development of Thermoacoustic Devices for Power Generation and Refrigeration. Proceedings of the Institution of Mechanical Engineers, Part A: Journal of Power and Energy, 227, 762-782. http://dx.doi.org/10.1177/0957650913493622 


\section{Nomenclature}

\begin{tabular}{|c|c|c|c|}
\hline$A_{f}$ & Mass air to fuel ratio & $R_{w}$ & Moisture content of fuel: mass water/mass fuel \\
\hline$C_{p a}$ & Specific heat air $=1.01, \mathrm{~kJ} / \mathrm{K}$ (at constant pressure) & $R \theta_{a}$ & $\begin{array}{l}\text { Total thermal resistance of AHX from working gas to } \\
\text { ambient, K/W }\end{array}$ \\
\hline$C_{p c}$ & Specific heat combustion gasses. (at constant pressure) & $R \theta_{c}$ & Effective thermal resistance of the combustion process \\
\hline$C_{p f}$ & Specific heat of fuel, $\mathrm{kJ} / \mathrm{K}$ (at constant pressure) & $R \theta_{h}$ & $\begin{array}{l}\text { Total thermal resistance of HHX from combustion gas to } \\
\text { Stirling working gas, K/watt }\end{array}$ \\
\hline$C_{p w}$ & Specific heat steam $=1.93, \mathrm{~kJ} / \mathrm{K}$ & $T_{a}$ & Ambient temperature, Kelvin \\
\hline$C_{v f}$ & Higher calorific value of fuel, $\mathrm{kJ} / \mathrm{kg}$ & $T_{c}$ & Temperature of the cold heat exchanger (AHX), Kelvin \\
\hline$L_{h}$ & Latent heat of evaporation of water $=2264 \mathrm{~kJ} / \mathrm{kg}$ & $T_{e}$ & Entry temperature to the heat engine, Kelvin \\
\hline$\dot{m}_{a}$ & Mass flow rate of air, $\mathrm{kg} / \mathrm{s}$ & $T_{f}$ & $\begin{array}{l}\text { Ideal flame temperature, assuming no dissociation of } \\
\text { component gasses }\end{array}$ \\
\hline$\dot{m}_{f}$ & Mass flow rate of fuel, $\mathrm{kg} / \mathrm{s}$ & $T_{h}$ & Temperature of the hot heat exchanger (HHX) in Kelvin \\
\hline$\dot{m}_{c}$ & Mass flow rate of combustion gasses, $\mathrm{kg} / \mathrm{s}$ & $W_{S E}$ & Work output from the engine, $\mathrm{W}$ \\
\hline$\dot{m}_{w}$ & Mass flow rate of water, $\mathrm{kg} / \mathrm{s}$ & $X_{s}$ & Mass ratio of air to stoichiometric air flow \\
\hline$Q_{c}$ & Heat available from combustion, watts & $\eta$ & Efficiency: work out/heat in \\
\hline$Q_{S E}$ & Amount of heat supplied to the Stirling engine, $\mathrm{W}$ & $\eta_{S E}$ & $\begin{array}{l}\text { The new efficiency of the Stirling engine: work out/heat from } \\
\text { combustion }\end{array}$ \\
\hline$r$ & Otto cycle compression ratio & $\gamma$ & $\begin{array}{l}\text { Ratio of specific heats at constant volume to constant } \\
\text { pressure }\end{array}$ \\
\hline
\end{tabular}

